\title{
Coproduction of place and knowledge for ecology with the city
}

\author{
Steward T. A. Pickett ${ }^{1}$ (D) Mary L. Cadenasso ${ }^{2} \cdot$ Anne M. Rademacher $^{3}$
}

Accepted: 16 November 2021 / Published online: 25 November 2021

(c) The Author(s) 2021

\begin{abstract}
Ecology with the city is a transdisciplinary pursuit, combining the work of researchers, policy makers, managers, and residents to advance equity and sustainability. This undertaking may be facilitated by understanding the parallels in two kinds of coproduction. First, is how urban systems themselves are places that are jointly constituted or coproduced by biophysical and social processes. Second, is how sustainable planning and policies also join human concerns with biophysical structures and processes. Seeking connections between coproduction of place and the coproduction of knowledge may help improve how urban ecology engages with diverse communities and urban interests in service of sustainability.
\end{abstract}

Keywords Production of place $\cdot$ Social-ecological-system $\cdot$ Sustainability $\cdot$ Transdisciplinary

Ecology with the city emphasizes reciprocal interactions among scientists, regulators, and residents in order to understand and manage the city in a more just and sustainable way (Byrne 2021). It addresses the persistent problem in urban ecology and its application of conceiving of people and nature in cities to be distinct from each other. Drawing from our extensive research experience in Baltimore, for example, we might raise a seemingly simple example: the act of planting trees on streets that lack them. On the one hand, incorporating trees in city streetscapes has been valued by Baltimore civic elites, developers, and homebuyers in some neighborhoods since the early twentieth century. On the other hand, some neighborhoods, for example those inhabited by recent European immigrants, had different ideas. In his history of urban forestry in Baltimore, Buckley (2010:171) notes that in 1955 city forester Charles Young remarked, "I was under the impression that all people like to have trees planted in front of their houses until I started planting trees in front of houses." Buckley goes on to quote Mrs. Joseph Lisiecki, a resident of East Baltimore, who expressed her preference for

Steward T. A. Pickett

picketts@caryinstitute.org

1 Cary Institute of Ecosystem Studies, Box AB, Millbrook, NY 12545, USA

2 Department of Plant Sciences, University of California, Davis, 1 Shields Ave., Davis, CA 95616, USA

3 New York University, Department of Environmental Studies, 285 Mercer Street, New York, NY 10003, USA "clean, uncluttered concrete." She continued, "If I wanted a tree, I'd move to the suburbs" (Fig. 1).

Ecology with the city helps to sort out this kind of contradiction between residents that have different preferences for trees. Tree-loving and tree-avoiding cultures are as much a part of the environment that city forests confront as heat, drought, pollution, and restricted rooting zones. This fact points to the social and biophysical coproduction of urban places. Biophysical features, built infrastructure, and social processes combine to create the structure of an urban ecosystem. Structure in this case is defined by the presence or absence of trees deemed desirable in a given neighborhood. But the fact that a city agency, in concert with wealthy elites, designed Baltimore city's mid-century tree planting strategy without knowing what all citizens desired or valued points to another kind of coproduction: the coproduction of actionable knowledge by residents, civic leaders, and forest researchers. The city forester's surprise at the existence and vehemence of opposition to city tree planting was a consequence of attempting to put into place a top down strategy that did not consider the wishes of local residents, that is, the strategy was not coproduced. Ecology with the city requires understanding both these kinds of coproduction: the socialbiophysical coproduction of urban places, and the coproduction of just, actionable knowledge that can be used in equitable ways for planning and managing the city.

The coproduction of place, and the coproduction of ecological knowledge for action, are each well known in distinct disciplinary realms; however, they have not been 
Fig. 1 City (A) and suburban (B) residential neighborhoods in Baltimore, MD illustrating the differences in tree cover and overall greening between them
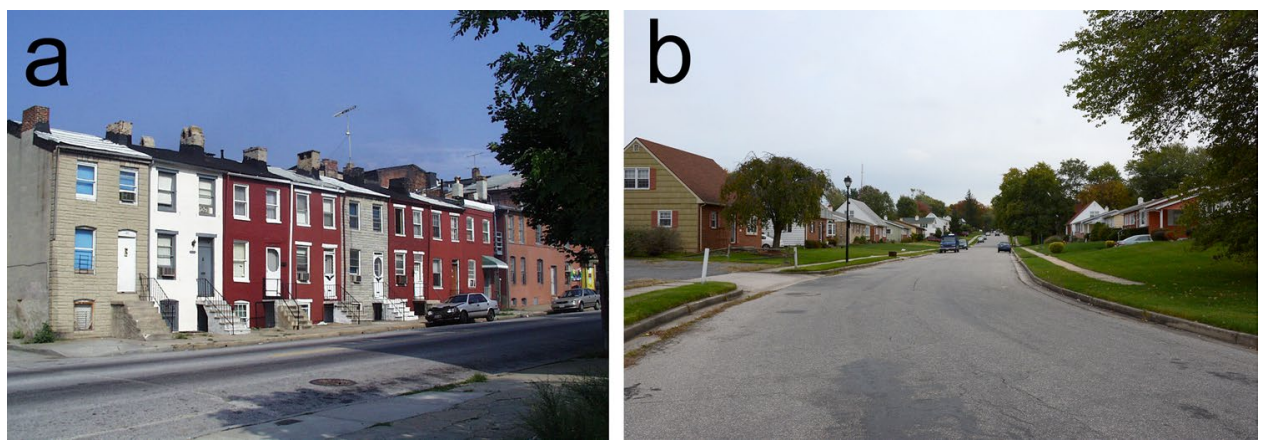

previously explored together. Joining these two important aspects of urban ecology and practice shows that the idea of ecology with the city is a substantial frontier in urban science and application. In this paper, we first examine the fundamental idea that urban places are, in all of their manifestations, hybrid social-biophysical places. They are therefore coproduced by the interactions of social processes and biophysical processes. Social processes include such things as group identity formation, institutional structures and networks, economic patterns, and power relations, among others. Biophysical processes and structures include resources such as nutrients and water, the environmental constraints on the use of resources, such as temperature and seasonality, and dynamics, such as disturbance and succession that exist in urban places.
Second, we summarize key attributes of the coproduction of knowledge intended to support the sustainability of cities. Finally, we integrate the coproduction of place with the coproduction of knowledge to demonstrate that ecology with the city has both theoretical and practical sides (Fig. 2). Since urban systems are themselves coproduced (Rademacher et al. 2019), and the knowledge for their best management, design, and revitalization as hybrid socialecological systems is also coproduced (Childers et al. 2015), ecology with the city represents an extraordinarily rich and new kind of coproduction. All the kinds of coproduction discussed here are ongoing processes. Therefore, ecology with the city engages ecologists in complex, reciprocal social-biophysical dynamics. That simple statement contains many ideas that we will elaborate below.

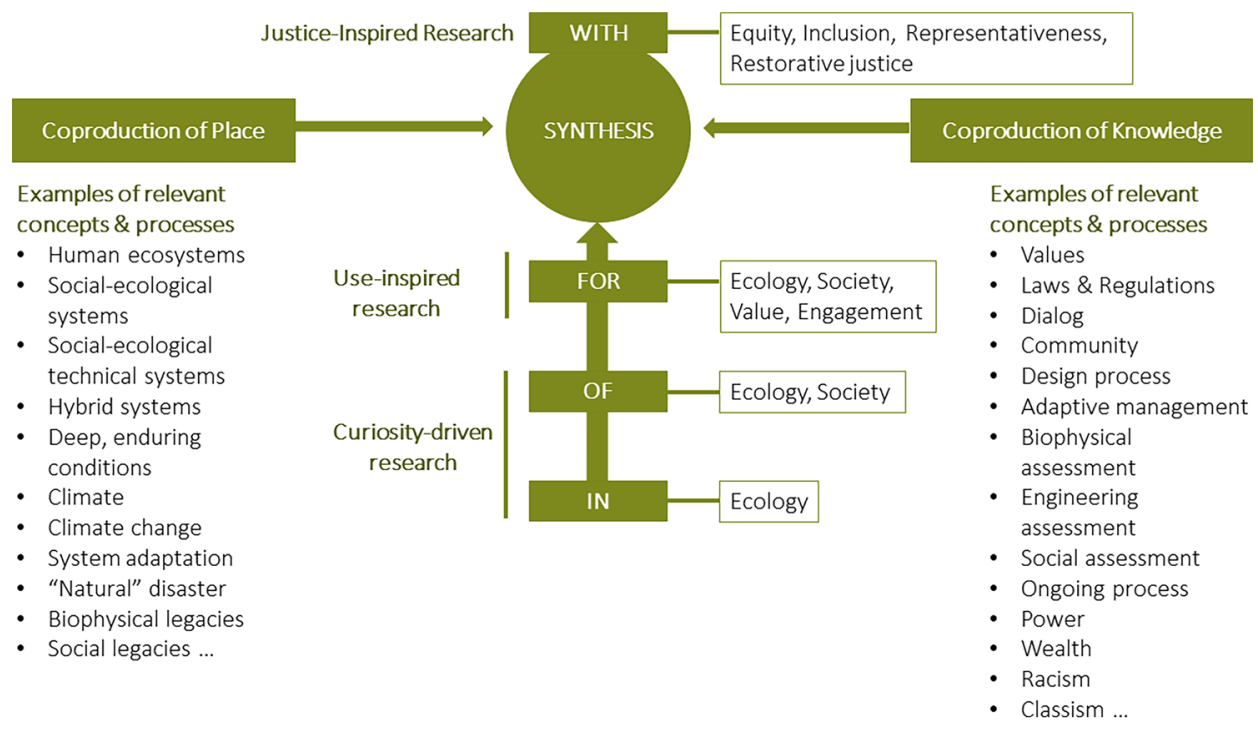

Fig. 2 The relationship of coproduction of place, coproduction of knowledge, and their synthesis to support research and action aimed at ecology with the city. The expansive relationship of ecology with the city emerges from the sequence of increasing breadth and social sensitivity of ecology in, ecology of (Pickett et al. 1997), and ecology for the city (Childers et al. 2015). Some examples of the concepts and processes of coproduction are associated with place and actionable knowledge. These lists are not comprehensive. The inspirations for research, shown to the left of the in, of, for, and with perspectives are informed by Stokes (1997) categorization of research as inspired by curiosity or by use. We add the aspiration that urban ecological research be inspired by environmental and social justice 


\section{Coproduction of place}

Social scientists and urbanists have long addressed the social construction of space or place (Lefebvre 1991), but this concept is less familiar in ecology. Invoking the phrase, "coproduction" of the city builds on the insight that social space isn't just an empty stage having an independent existence (Gottdiener 1985). Instead, urban places are intentionally constructed, landscaped, used, or set aside. That is to say, all space - including natural or "green" space - comes to exist, and is reproduced, in part because of social interactions and human attributions of social meaning (Rademacher and Sivaramakrishnan 2017). Competing attributions of social meaning can, and often do, emerge from negotiation, conflict, or authority as seen in the opposition to city tree planting by local Baltimore residents. The recognition that urban places are produced both by biophysical and social processes is fundamental. However, most of the literature discussing social creation of space neglects the biophysical aspects of urban places.

The literature in social sciences and humanities theorizes cities as natural-social hybrids (e.g. Braun 2005; Demeritt 1994; Haraway 1991, 1997; Latour 1993, 1999; Swyngedouw 1996, 2006; Zimmerer 2000). However, the operational practice of understanding the actual socialnatural change patterns remains to be worked out. Furthermore, this desired operationalization can benefit from fuller incorporation of the growing biophysical understanding of cities to complement the already well developed social theory of nature-culture integration.

Urban design and planning have a parallel tradition of noting the social construction of place (McHarg 1969; Spirn 1984, 2012; Palazzo and Steiner 2011; Steiner et al. 2016). McHarg's classic Design With Nature (1969) emphasized that design and planning decisions must account for distributions of cultural, historical, and natural resources across a landscape. Spirn (1984) took this idea into established urban places, and combined it with concerns for social equity and power differentials. She did this in order to understand the environmental threats, hazards, and opportunities that are both the outcomes of past design decisions and the targets for desired improvements for all persons in an urban area. It is a short step from these practices to the insight that urban areas are hybrid places, and that they are therefore coproduced by the things that McHarg and Spirn identify as key tools and approaches for urban design. The phrase, "blended or dissolved natural-social milieu," is another design-oriented way to express the multifaceted emergence of urban systems (Barnett 2013:6), and Steiner et al. (2016) clearly link the idea of urban places as hybrids with sustainability goals and planning. Cronon (1991) environmental and economic history of Chicago is another compelling case of coproduction of a city. He used the term "second nature" to signal the hybrid nature of this urban place in its regional context.

Within urban ecology itself, the hybrid nature of cities has been clearly identified as a foundation for the science (Grimm et al. 2000). The last two decades of urban ecology research involving both social and biophysical scientists have emphasized that human settlements are hybrid systems (Cadenasso et al. 2006; Pickett et al. 2011; Zhou et al. 2017). Cities, suburbs, towns, and exurbs consist of altered land surfaces, buildings, extensive infrastructures, and modified substrates and landforms; all of these influence flows of water, materials, and air. But cities can also retain native soils and vegetation in places, or host remnant or newly established populations of plants, animals, and microbes. Processes like physiological acclimation, behavioral adjustment, and evolution of organisms continue or accelerate in urban places (Johnson and Munshi-South 2017). This increasingly widely recognized hybridity (Boone and Fragkias 2012; Grimm et al. 2016) means that urban settlements are necessarily coproduced by the intimate interactions of biophysical and social structures, processes, and actions (Rademacher et al. 2019). Coproduction of place refers to the ongoing process by which the substance of the urban place itself is created by biophysical and social features and their interactions.

One example of how coproduction of place can shape a researcher's approach to urban environmental change is illustrated in Lachmund's (2013) study of the origin and significance of Berlin's public green spaces. His work investigates how Berlin's "natural" spaces were a distinctly hybrid or coproduction of science, politics, and nature. Science and politics were engaged in a bidirectional, and sometimes contentious relationship that in the decades since World War II, enabled researchers, conservationists, and politicians to set aside, and in some ways cultivate, those green sites.

A second example is how urban land classification can be improved by taking a hybrid approach. Rather than assuming that urban and nature are necessarily distinct and nonoverlapping places, the pioneering HERCULES land cover classification, the first of many that were to follow, was built on the assumption that cities are hybrids. This classification is patch based and integrates the relative cover of buildings, surfaces, and vegetation in each patch (Cadenasso et al. 2007). Therefore, it explicitly recognizes that the urban system is coproduced (Marshall et al. 2020).

Disturbance in urban systems provides our final example of coproduction of place. Disturbance events that affect urban systems take many forms (Grimm et al. 2017). Coastal flooding, inundation of streets and low spots after torrential rains, and fire, tornado, hurricane, or landslides are some of the many kinds of events that can physically disrupt the 
urban fabric, interrupt urban system functions, and threaten human life and wellbeing. A mounting body of evidence, some from social science and some from ecology, has shown that "natural disturbance" or catastrophe in urban places is as much the result of human decisions, actions, and legacies as they are the result of the motive power of wind and water, or the consumptive power of fire (Grimm et al. 2017). It is becoming commonplace to say that disasters occur "by design" (Mileti 2008), meaning for example that mortality from heat waves emerges not only from excessive temperature and humidity over long periods, but also from lapses in civil processes such as warning, access to cooling centers, or socially differentiated disadvantage (Changnon et al. 1996; Duneier 2004; Kleinenberg 2015), as well as individual people's medical vulnerabilities. Recent analyses of disturbance as a recurring and formative process in cities has shown that human-built structures and human actions combine with the force of events generated by weather and earth movements (Grimm et al. 2017). It is impossible to analyze disturbance in urban systems and not join human and biophysical drivers and agency. Disturbance as a process in urban systems is coproduced by the intersection of social-ecological-system components with some usually externally triggered event.

The fundamental idea that urban systems of all sorts are social-natural hybrids, coproduced by closely intertwined biophysical and social processes, is a clear insight from several decades of progress in integrated urban ecological research (Cadenasso and Pickett 2019). This insight must be linked with the understanding of urban ecological knowledge as a coproduct as well.

\section{Coproduction of knowledge for action}

The more familiar use of coproduction in urban ecology is one that refers to socially embedded research, engagement, and communication (Ostrom 1996). Coproduction here refers to the generation of scientific knowledge based on ongoing, mutually respectful, multi-way interactions among researchers, policy makers, managers, residents, and civil society (Goodwin 2019; Groffman et al. 2010). Coproduction of knowledge for action must acknowledge a deeper way in which science itself is embedded in a social context of power relationships (e.g. Jasanoff 2004). This aspect of coproduction is familiar to many social scientists as a concept employed in Science and Technology Studies. It understands that any form of scientific knowledge is formulated by human social agents -scientists - who are themselves positioned in a web of social dynamics and power relations. Science is often considered to occupy a privileged position in such networks, and the process by which actionable knowledge is coproduced must actively avoid excluding or devaluing the voices of the less powerful. Such coproduction acknowledges that the rationales, ethics, and practices of ecological research have social context and power relationships (May and Perry 2017; Perry et al. 2018). Coproduction aimed at generating environmentally and socially favorable outcomes for urban places must cultivate partnerships that honor the different rationales, ethics, and practices of diverse social actors (Krasny et al. 2014).

Coproduction of knowledge is not just "better" information transfer, or even comprehensive integration across all relevant disciplines. Instead, coproduction of knowledge integrates only what the situation and the community requires for action (Lam et al. 2019). The partners must together select what works for the group and the problem they are addressing. A statement from West et al. (2019:534) reinforces this point: "Knowledge is not 'applied to' action, but drawn upon, produced and used from within the situation at hand." The simple act of referring to a "situation" automatically includes the problem and the social partnership together (Star and Griesemer 1989). And any social partnership likely has power relationships that can be barriers to generating and using coproduced knowledge (Perry et al. 2018).

Coproduction in this sense of shared knowledge production is akin to transdisciplinarity (e.g. Gordon et al. 2019). Transdisciplinarity, is sometimes used to describe the most integrative scientific pursuit, building on multidisciplinary and interdisciplinary (Ramadier 2004). Coproduction as shared knowledge production, however, readily suggests a product and a process. The "co" means nothing less than generating questions, pursuing knowledge, enacting transformations, and assessing outcomes together. Coproduction, therefore, has the potential to enhance procedural justice by including the social community and can advance distributional justice through the joint enaction of transformations.

\section{Integrating coproduction of place and coproduction of knowledge}

We have shown that coproduction has at least two important, complementary meanings fundamental to ecology with the city. The first is the process by which the hybrid socialbiophysical nature of cities is itself created. We assert, with increasing literature support, that cities are coproduced. The full implications of this have not been brought into the science and practice of intervening in cities. The second use of coproduction is as a transdisciplinary, socially just way to generate knowledge and action to improve both environmental and human wellbeing in cities. Science-Technology Studies remind us that the partnerships are forged in social realities that represent already prefigured potential inequities of power and assumed authority. Furthermore, it reminds us that even scientific knowledge comes into being through 
the work of social agents and so can be influenced by that structure-function-agency.

Let us consider a practical example of the coproduction of knowledge in action. We point, for example, to the Baltimore Wood Project which unfolded in the context of our broader work with the Baltimore Ecosystem Study (BES; Pickett et al. 2020) including its evolution toward a Baltimore ecosystem alliance (Grove and Pickett 2019). The Baltimore Wood Project (n.d.) is based on work organized by the USDA Forest Service in close interaction with Baltimore City agencies, and environmental and sociallyoriented non-profits. This partnership generated scientific knowledge, showing that the wood from tree felling or maintenance in the city could serve as a reusable resource. This could reduce the waste stream, provide opportunities for training and employment of underserved communities, and generate economically profitable products. The partnership also identified the large number of abandoned buildings as a surprising source of old-growth yellow pine in the internal framing of buildings slated for demolition. This old growth, dense-grained wood was timber that no longer existed in the wild. Deconstructing - rather than demolishing these buildings - generated training and employment for residents facing social and economic challenges, while providing a profitable source of timber that could be sold to produce new furniture. Rarely does a discourse based in science yield such a variety of socially and economically beneficial outcomes. Yet by deliberately working in a way that seeks the coproduction of actionable knowledge, such examples could become the norm.

The relationship between the two kinds of coproduction - of place and of knowledge - may improve how we think about and plan for sustainable urban futures (Fig. 1). The structure of the argument is revealed by the combination of two statements below:

- If cities are indeed hybrids of biophysical processes and structures along with social structures and processes, then the plans, interventions, assessments, and adaptations of cities to the massive changes confronting them must account for the intimate and simultaneous connections between these two kinds of urban components (Rademacher et al. 2019).

- If coproduction is a deep and abiding partnership to generate actionable knowledge with the city (Muñoz-Erickson et al. 2017), then that knowledge must also account for the more fundamental coproduced biophysical and social nature of the city itself.

Together these statements suggest that there must be learning on all sides of the conversation to achieve the benefits of "coproduction X coproduction." Cities are traditionally siloed into distinct functions addressed by different governmental departments or managerial interest groups. The role of biophysical processes, other than as the driver of a hazard, may be minimized or neglected entirely by this siloed organization. Similarly limited may be the way that biological ecologists view the city. Ecologists may focus on seemingly neutral "space" for installing green infrastructure and neglect the different and even conflicting social values associated with that space. This focus may likewise neglect the crowded below-ground volume that is notoriously infused with pipes, conduits, tunnels, and the legacies of prior foundations and works. Thus, green infrastructure planning is constrained by several dimensions of coproduced urban complexity, including the differential power relationships among city residents, science, and decision leaders.

Taking the experience, successes, and lessons learned from the growing interest in ecology for the city (Childers et al. 2015) and with the city (Byrne 2021) will only strengthen and extend how we use the two parallel dimensions of coproduction. We invoked two examples from Baltimore to summarize the practical value of integrating coproduction of place and coproduction of knowledge. The consternation exhibited by the interaction of the Baltimore City forester and Mrs. Joseph Lisiecki in 1955 illustrates what can happen when the two kinds of coproduction are not engaged. The forester was likely employing a technocratic view of the city and his job: bringing the built environment and nature together. The homeowner was likely expressing a long-standing cultural stance that the city and nature were separate things. Neither of these "actors" saw the city as a coproduced place. That is, the goal of planting trees in front of people's houses had not emerged from a respectful, open dialogue about environmental needs, goals, burdens, and options. Much of East Baltimore, where Mrs. Lisiecki used to live, is still devoid of trees. Contemporary greening efforts in Baltimore, however, occupy a strategic place very much congruent with the intersection of the two kinds of coproduction we bring together. The Baltimore Wood Project (n.d.; BWP), being a more recent "invention," has occupied what we would called earlier a coproduction X coproduction space (Fig. 2) from its inception. From the perspective of coproduction of knowledge, the BWP prioritizes such things as neighborhood social vitality, providing training and jobs to persons often excluded from those resources by their histories with the criminal justice system, or by other limitations imposed by poverty, scant transportation options, and lack of opportunities for employment. However, the deconstruction of rowhouses to exploit the old growth timber embedded in them is a powerful recognition that the material fabric of the city is coproduced. The yellow pine wood being recycled for profit and for benefit to the residents is an irreplaceable resource that was hidden in the urban fabric. The partnership behind the BWP was initiated by researchers who revealed the resource to community activists, entrepreneurs, 
and businesses. These two examples show that the conceptual depth at the intersection of coproduction of place and coproduction of knowledge have the power to both improve how we think about the city, but also to improve practical environmental problem solving, equity, and vitality of cities. With these two examples, we highlight that identifying problems and solutions is still difficult, since power differentials and social heterogeneity still vex the dialogue, but diverse participants are now more regularly engaged in the process of ongoing coproduction of their city spaces. We assert that integrating coproduction of place and knowledge in any urbanized situation can be a powerful way to operationalize the ecology with the city.

Author contribution The authors equally shared in conception and writing of the paper.

Funding The research was supported by the U.S. National Science Foundation, Division of Environmental Biology DEB1637661 and DEB 1855277.

\section{Declarations}

Ethics approval Not applicable.

Research involving human/animal participants Not applicable.

Consent to participate Not applicable.

Conflict of interest The authors declare no conflicts of interest.

Open Access This article is licensed under a Creative Commons Attribution 4.0 International License, which permits use, sharing, adaptation, distribution and reproduction in any medium or format, as long as you give appropriate credit to the original author(s) and the source, provide a link to the Creative Commons licence, and indicate if changes were made. The images or other third party material in this article are included in the article's Creative Commons licence, unless indicated otherwise in a credit line to the material. If material is not included in the article's Creative Commons licence and your intended use is not permitted by statutory regulation or exceeds the permitted use, you will need to obtain permission directly from the copyright holder. To view a copy of this licence, visit http://creativecommons.org/licenses/by/4.0/.

\section{References}

Baltimore Wood Project (n.d.) Rethinking wood in the city. http:// baltimorewoodproject.org/. Accessed 30 Mar 2021

Barnett R (2013) Emergence in landscape architecture. Routledge, New York

Boone CG, Fragkias M (2012) Urbanization and sustainability: Linking urban ecology, environmental justice and global environmental change. Springer, New York

Braun B (2005) Environmental issues: Writing a more-than-human urban geography. Prog Hum Geogr 29(5):635-650. https://doi. org/10.1191/0309132505ph574pr
Buckley GL (2010) America's conservation impulse: a century of saving trees in the Old Line State. The Center for American Places at Columbia College Chicago, Chicago

Byrne L (2021) Ecology with the city: A new feature in urban ecosystems. Urban Ecosyst

Cadenasso ML, Pickett STA (2019) Principles of urban ecological science: insights from the Baltimore school of urban ecology. In: Pickett STA, Cadenasso ML, Grove JM, Irwin EG, Rosi EJ, Swan $\mathrm{CM}$ (eds) Science for the sustainable city: Empirical insights from the Baltimore school of urban ecology. Yale University Press, New Haven, pp 251-285

Cadenasso ML, Pickett STA, Grove JM (2006) Integrative approaches to investigating human-natural systems: the Baltimore ecosystem study. Natures Sciences Societes 14:4-14

Cadenasso ML, Pickett STA, Schwarz K (2007) Spatial heterogeneity in urban ecosystems: Reconceptualizing land cover and a framework for classification. Front Ecol Environ 5:80-88. https://doi. org/10.1890/1540-9295(2007)5[80:SHIUER]2.0.CO;2

Changnon SA, Kunkel KE, Reinke BC (1996) Impacts and responses to the 1995 heat wave: a call to action. Bull Am Meteor Soc 77:1497-1506. https://doi.org/10.1175/1520-0477(1996)077\% 3c1497:IARTTH\%3e2.0.CO;2

Childers DL, Cadenasso ML, Grove JM, Marshall V, McGrath B, Pickett STA (2015) An ecology for cities: a transformational nexus of design and ecology to advance climate change resilience and urban sustainability. Sustainability 7:3774-3791. https://doi. org/10.3390/su7043774

Cronon W (1991) Nature's metropolis: Chicago and the Great West. Norton, New York, W.W

Demeritt D (1994) The nature of metaphors in cultural-geography and environmental history. Prog Hum Geogr 18:163-185. https://doi. org/10.1177/030913259401800203

Duneier M (2004) Scrutinizing the heat: on ethnic myths and the importance of shoe leather. Contemp Sociol 33:139-150. https:// doi.org/10.1177/009430610403300203

Goodwin G (2019) The problem and promise of coproduction: politics, history, and autonomy. World Dev 122:501-513. https://doi.org/ 10.1016/j.worlddev.2019.06.007

Gordon IJ, Bawa K, Bammer G, Boone C, Dunne J, Hart D et al (2019) Forging future organizational leaders for sustainability science. Nat Sustain 2:647-649. https://doi.org/10.1038/ s41893-019-0357-4

Gottdiener M (1985) The social production of urban space, 2nd edn. University of Texas Press, Austin

Grimm N, Grove JM, Pickett STA, Redman C (2000) Integrated approaches to long-term studies of urban ecological systems. Bioscience 50:571-584

Grimm NB, Cook EM, Hale RL, Iwaniec DM (2016) A broader framing of ecosystem services in cities: Benefits and challenges of built, natural, or hybrid system function. In: Seto KC, Solecki WD, Griffith CA (eds) The Routledge handbook of urbanization and global environmental change. Routledge, New York, pp 203-212

Grimm NB, Pickett STA, Hale RL, Cadenasso ML (2017) Does the ecological concept of disturbance have utility in urban socialecological-technological systems? Ecosyst Health Sustain 3(1). https://doi.org/10.1002/ehs2.1255

Groffman PM, Stylinski C, Nisbet MC, Duarte CM, Jordan R, Burgin AJ et al (2010) Restarting the conversation: Challenges at the interface between ecology and society. Front Ecol Environ 8. https://doi.org/10.1890/09016

Grove JM, Pickett STA (2019) From transdisciplinary projects to platforms: expanding capacity and impact of land systems knowledge 
and decision making. Curr Opin Environ Sustain 387-13. https:// doi.org/10.1016/j.cosust.2019.04.001

Haraway D (1991) Simians, cyborgs, and women: the reinvention of nature. Routledge, New York

Haraway D (1997) Modest witness@ second millennium. Femaleman meets Oncomouse: Feminism and technoscience. Psychology Press, New York

Jasanoff S (ed) (2004) States of knowledge: the co-production of science and social order. Routledge, Taylor \& Francis Group, New York

Johnson MTJ, Munshi-South J (2017) Evolution of life in urban environments. Science 358(6363):seaam8327. https://doi.org/10.1126/ science.aam 8327

Kleinenberg E (2015) Heat wave: a social autopsy of disaster in Chicago, 2nd edn. University of Chicago Press, Chicago

Krasny ME, Russ A, Tidball KG, Elmqvist T (2014) Civic ecology practices: Participatory approaches to generating and measuring ecosystem services in cities. Ecosyst Serv 7:177-186. https://doi. org/10.1016/j.ecoser.2013.11.002

Lachmund J (2013) Greening Berlin. MIT Press, Cambridge

Lam S, Thompson M, Johnson K, Fioret C, Hargreaves SK (2019) Toward community food security through transdisciplinary action research. Action Res UNSP 1476750319889390. https://doi.org/ $10.1177 / 1476750319889390$

Latour B (1993) We have never been modern. Harvard University Press, Cambridge

Latour B (1999) Pandora's hope: Essays on the reality of science studies. Harvard University Press, Cambridge

Lefebvre H (1991) The production of space. Blackwell, Oxford

Marshall V, Cadenasso ML, McGrath B, Pickett STA (2020) Patch atlas: Integrating design practices and ecological knowledge for cities as complex systems. Yale University Press, New Haven

May T, Perry B (2017) Knowledge for just urban sustainability. Local Environ 22:23-35. https://doi.org/10.1080/13549839.2016.1233527

McHarg IL (1969) Design with nature. Natural History Press, Garden City, NY

Mileti DS (2008) Disasters by design: a reassessment of natural hazards in the United States. Joseph Henry Press, Washington

Muñoz-Erickson TA, Miller CA, Miller TR (2017) How cities think: Knowledge co-production for urban sustainability and resilience. Forests 8:203. https://doi.org/10.3390/f8060203

Ostrom E (1996) Crossing the great divide: Coproduction, synergy, and development. World Dev 24(6):1073-1087

Palazzo D, Steiner F (2011) Urban ecological design: a process for regenerative places. Island Press, Washington

Perry B, Patel Z, Bretzer YN, Polk M (2018) Organising for co-production: Local interaction platforms for urban sustainability. Politics Gov 6:189-198. https://doi.org/10.17645/pag.v6i1.1228

Pickett STA, Burch WR Jr, Dalton SE, Foresman TW (1997) Urban Ecosystems 1(4):183-184. https://doi.org/10.1023/A:1018579628818
Pickett STA, Cadenasso ML, Grove JM, Boone CG, Groffman PM, Irwin EG et al (2011) Urban ecological systems: Scientific foundations and a decade of progress. J Environ Manage 92(3):331362. https://doi.org/10.1016/j.jenvman.2010.08.022

Pickett STA et al (2020) Theoretical perspectives of the Baltimore ecosystem study: Conceptual evolution in a social-ecological research project. Bioscience. https://doi.org/10.1093/biosci/biz166

Rademacher A, Sivaramakrishnan K (eds) (2017) Places of nature in ecologies of urbanism. Hong Kong University Press, Hong Kong

Rademacher A, Cadenasso ML, Pickett STA (2019) From feedbacks to coproduction: Toward an integrated conceptual framework for urban ecosystems. Urban Ecosyst 22:65-76. https://doi.org/10. 1007/s11252-018-0751-0

Ramadier T (2004) Transdisciplinarity and its challenges: The case of urban studies. Futures 36:423-439. https://doi.org/10.1016/j. futures.2003.10.009

Spirn AW (1984) The granite garden: Urban nature and human design. Books, New York

Spirn AW (2012) Ecological urbanism: a framework for the design of resilient cities. Retrieved from http://www.annewhistonspirn.com/ pdf/Spirn-EcoUrbanism-2012.pdf

Star SL, Griesemer JR (1989) Institutional ecology, translations and boundary objects: amateurs and professionals in Berkeley's Museum of Vertebrate Zoology, 1907-39. Soc Stud Sci 19(3):387-420

Steiner FR, Thompson GF, Carbonell A (eds) (2016) Nature and cities: The ecological imperative in urban design and planning. The Lincoln Institute of Land Policy, Cambridge

Stokes DE (1997) Pasteur's quadrant: Basic science and technological innovation. Brookings Institution Press, Washington, D.C.

Swyngedouw E (1996) The city as a hybrid: on nature, society and cyborg urbanization. Capital Nat Social 7(2):65-80. https://doi. org/10.1080/10455759609358679

Swyngedouw E (2006) Circulations and metabolisms: (hybrid) natures and (cyborg) cities. Science as Culture 15(2):105-121. https://doi. org/10.1080/09505430600707970

West S, van Kerkhoff L, Wagenaar H (2019) Beyond linking knowledge and action: towards a practice-based approach to transdisciplinary sustainability interventions. Pol Stud 40(5):534-555. https://doi. org/10.1080/01442872.2019.1618810

Zhou W, Pickett STA, Cadenasso ML (2017) Shifting concepts of urban spatial heterogeneity and their implications for sustainability. Landscape Ecol 32(1):15-30. https://doi.org/10.1007/ s10980-016-0432-4

Zimmerer KS (2000) The reworking of conservation geographies: Nonequilibrium landscapes and nature-society hybrids. Ann Assoc Am Geogr 90(2):356-369. https://doi.org/10.1111/0004-5608. 00199 